\title{
Amateur soccer: injuries in relation to field position
}

\author{
M. Hunt MB, FRCSEd and S. Fulford MB BS \\ Accident and Emergency Department, King's College Hospital, London, UK
}

There is little information in the current sports literature regarding injury patterns and position of play in amateur or professional soccer matches. Lewin ${ }^{1}$, reporting injuries sustained at Arsenal football club, stated: 'One aspect not covered in this survey was the relevance of players' position to the incidence of injury".

This study examines the types of injuries occurring in amateur football players presenting to the accident and emergency department of King's College Hospital in relation to the position of play on the field.

\section{Patients and methods}

During the 1988-9 soccer season information regarding 200 consecutive patients attending the accident and emergency (A and E) department at King's College Hospital with injuries sustained during amateur soccer matches was

Table 1. Injury frequency in relation to position of play

\begin{tabular}{llc}
\hline Position code & \multicolumn{1}{c}{ Field position } & Injury frequency \\
\hline A & Goalkeeper & $28(14 \%)$ \\
B & Right full-back & $20(10 \%)$ \\
C & Left full-back & $20(10 \%)$ \\
D & Right half-back & $4(2 \%)$ \\
E & Left half-back & $1(0.5 \%)$ \\
F & Centre half & $71(35.5 \%)$ \\
G & Outside left (forward) & $3(1.5 \%)$ \\
I & Inside right (forward) & $3(1.5 \%)$ \\
J & Centre forward & $33(16.5 \%)$ \\
K & Inside left (forward) & $1(0.5 \%)$ \\
L & Outside right (forward) & $5(2.5 \%)$ \\
M & Referee & $1(0.5 \%)$ \\
\hline
\end{tabular}

recorded. Details of playing position, injuries sustained, investigation and treatment were noted.

\section{Results}

The age range of players was 10 to 45 years, $67 \%$ of players in the age range 11 to 30 years, most frequent attenders being in the 21 to 35 age group (30\%). Ninety-nine percent of players were male. Seventy-seven percent of players attended for treatment within 24 hours, the remainder up to 4 weeks from the time of injury.

Those players directly involved in attack or defence are those most likely to be injured. The centre half, centreforward, full-backs and goalkeeper constituted $86 \%$ of players presenting for treatment (Table 1).

The most common injuries were those to the lower limb, $113(56.5 \%)$ of 200 injuries each player having a single injury. A significant proportion of injuries occurred to the upper limb, $54(27 \%)$ a high number of these occurred in the goalkeeper, and were mainly injuries to the thumb $(9 \%)$. Eighteen percent of players other than the goalkeeper sustained upper limb injuries due to falls. These injuries were to the elbows, wrists and hands and sustained predominantly by the full-backs, centre-forwards and centre-halves.

Sprains, fractures and bruises were the injuries most likely to occur (Table 2). Of the 66 cases of ankle injury, 42 were X-rayed, 39 showed no bony abnormality, in the remainder an old injury was demonstrated.

$A$ variety of self-treatments were used, before attendance in $A$ and $E$, by the players who sustained ankle injuries. Sixty percent employed rest, $44 \%$ strapping, $36 \%$ applied hot compresses, $28 \%$ elevation and ice packs, and $15 \%$ various topical applications.

Table 2. Type of injury in relation to position of play

\begin{tabular}{|c|c|c|c|c|c|c|c|c|c|c|c|c|c|c|}
\hline Postion code & $A$ & $B$ & $C$ & $D$ & $E$ & $\boldsymbol{F}$ & $G$ & $H$ & 1 & $J$ & $K$ & $L$ & $M$ & Total \\
\hline $\begin{array}{l}\text { Sprain (ankle) } \\
\text { Fracture } \\
\text { Bruise } \\
\text { Laceration } \\
\text { Other } \\
\text { Dislocation } \\
\text { Head injury } \\
\text { No record } \\
\text { Graze }\end{array}$ & $\begin{array}{l}8 \\
9 \\
6 \\
1 \\
1 \\
2 \\
1 \\
-\end{array}$ & $\begin{array}{l}7 \\
6 \\
3 \\
1 \\
2 \\
1 \\
- \\
-\end{array}$ & $\begin{array}{l}5 \\
9 \\
4 \\
1 \\
- \\
- \\
- \\
1\end{array}$ & $\begin{array}{l}2 \\
1 \\
1 \\
- \\
- \\
- \\
- \\
-\end{array}$ & $\begin{array}{l}1 \\
- \\
z \\
- \\
- \\
-\end{array}$ & $\begin{array}{r}21 \\
16 \\
19 \\
5 \\
4 \\
1 \\
2 \\
2 \\
1\end{array}$ & $\begin{array}{l}2 \\
1 \\
- \\
- \\
- \\
- \\
-\end{array}$ & $\begin{array}{l}\overline{1} \\
- \\
- \\
- \\
- \\
-\end{array}$ & $\begin{array}{r}12 \\
11 \\
8 \\
- \\
- \\
1 \\
-1\end{array}$ & $\begin{array}{l}1 \\
1 \\
1 \\
- \\
- \\
- \\
- \\
-\end{array}$ & $\begin{array}{l}1 \\
\overline{-} \\
2 \\
2 \\
- \\
- \\
-\end{array}$ & $\begin{array}{l}\overline{1} \\
- \\
- \\
- \\
- \\
-\end{array}$ & $\begin{array}{l}5 \\
1 \\
1 \\
1 \\
1 \\
1 \\
- \\
-\end{array}$ & $\begin{array}{r}66 \\
58 \\
43 \\
11 \\
10 \\
4 \\
4 \\
3 \\
2\end{array}$ \\
\hline Total & 28 & 20 & 20 & 4 & 1 & 71 & 3 & 1 & 33 & 3 & 5 & 1 & 10 & 200 \\
\hline
\end{tabular}

Address for correspondence: Martin Hunt, Accident and Emergency Department, Kings College Hospital, Denmark Hill, London SE5 9RS, UK

(C) 1990 Butterworth-Heinemann Ltd 0306-3674/90/040265-01

\section{Reference}

1 Lewin, G. The incidence of injury in an English professional soccer club during one competitive season Physiotherapy 1989, 75 (10) 